\title{
Evaluation of Interleukin- 6 in Lymphoma
}

\author{
Anfal Saleh Mohammed AL-jubory*, Sanaa Mohammed Taib Al- Hayali** \\ *Postgraduate Student , Department of Pathology, College of Medicine, University of Mosul , \\ **Department of Pathology, College of Medicine, University of Mosul , Mosul , Iraq \\ Correspondence: asanfal748@gmail.com
}

(Ann Coll Med Mosul 2020; 42 (2):162-168).

Received: 19 $9^{\text {th }}$ Oct. 2020; Accepted: $1^{\text {st }}$ Dec. 2020.

\begin{abstract}
Background: Cytokines play a pivotal role in lymphoma ,cytokines either can be produced or exert effects on neoplastic or reactive cells. The elevated level of cytokines can contribute to the clinical and histopathologic alterations associated with malignant lymphoma.

Objectives: to assess the level of IL- 6 in newly diagnosed lymphoma patients in relation to their level in normal control subjects and to evaluate the correlation between IL-6 and hemoglobin ( $\mathrm{Hb})$, stage of disease and B-symptoms, age and sex.

Methods: This is a case control study, a total of 40 patients with lymphoma (HL \& NHL) who attended private Clincs and hospitals in Mosul city and 40 age and sex matched control were included. A venous blood sample were taken for Complete blood count, Retic and IL-6 level. Enzyme-linked immunosorbent assay(ELISA)was used to determined IL-6 level.

Results: There were a significant difference between the mean level of IL- 6 of lymphoma cases and control ( $p$-value $=0.00$ ). In the subset of patients with anemia, IL-6 levels inversely correlated with hemoglobin levels $(p$-value $=0.00)$. There was significant correlation between IL-6 and patients with more advanced stage IIIIV disease ( $p$-value $=0.04)$. there was positive correlation between IL-6 level and B-symptoms) $p=0.05$ )

Conclusion: IL-6 level was elevated in lymphoma and it was significantly higher in lymphoma patients .IL-6 plays important role in the development of anemia in lymphoma. The adverse impact of elevated IL- 6 is consistent with demonstration of higher level of IL-6 in patients with advanced stage of disease.
\end{abstract}

Keywords: Lymphoma,IL-6,complete blood count,retic count.

$$
\begin{aligned}
& \text { تقيبم الانترليوكين-7 بالورم اللمفي }
\end{aligned}
$$

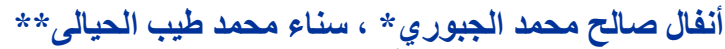

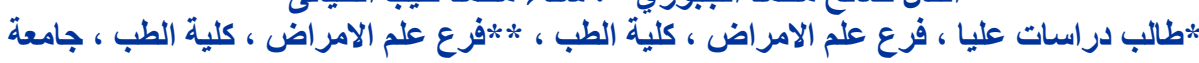

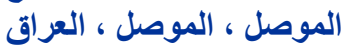

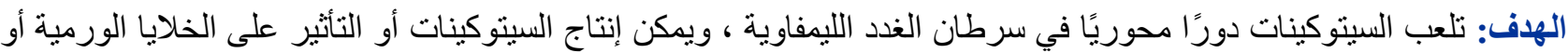

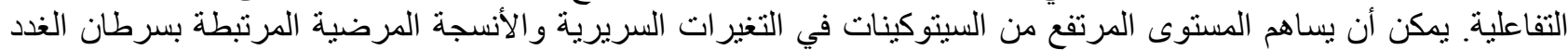

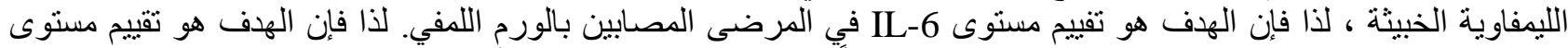

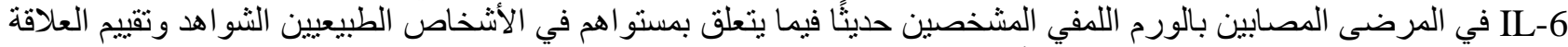

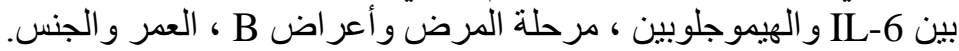

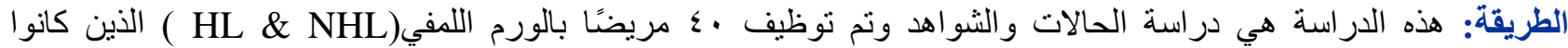

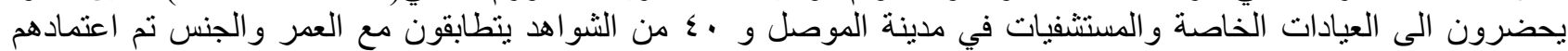

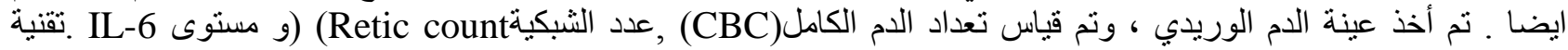

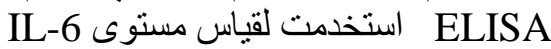

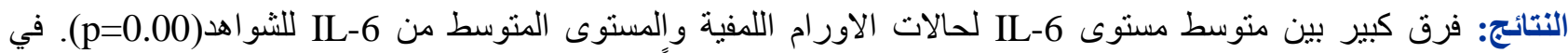

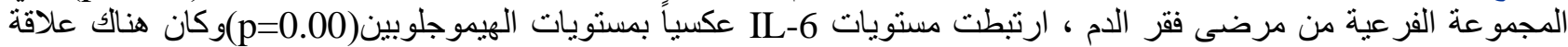

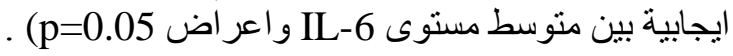




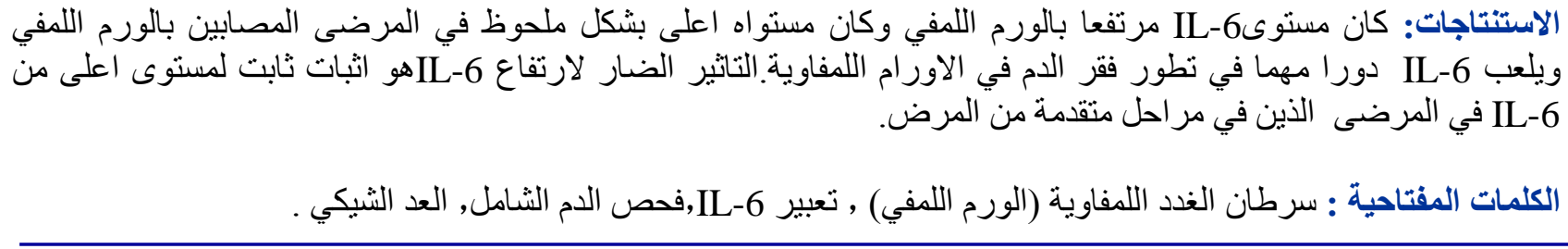

\section{INTRODUCTION}

$M$ alignant lymphoma is the basic term known to tumors of the lymphocyte whether of $T$ or B phenotype. It furthermore comprises tumors made up of histiocytes and further cells of immune system 1

It is first and foremost divided into Hodgkin's and non-Hodgkin's lymphoma ${ }^{2}$

Lymphadenopathy is the main complain of lymphoma patients that has been identified either accidentally by the patient or by imaging techniques performed for evaluation of other conditions, so often it might be recognized when examination of vague indications, for example, fever, weariness, or unexplained agony brief appraisal that thusly uncover mass sore ${ }^{3}$

One of the significant clinical highlights in lymphoma tolerant is anemia,which is common in malignant growth and lymphoproliferative disorder (LPD) ${ }^{4}$.

There are high level of cytokines, such interleukin-6 (IL-6), interleukin -10 (IL-10) result from the associations between" the reactive cells of the microenvironment and the neoplastic cells " 5 .

IL-6 is the most cytokines connected with anemia ${ }^{6}$ and it is a multifunctional cytokine that influences the activity of cancer cells"

IL-6 is a powerful inducer of hepcidin expression through a signal transducer and activator of transcription 3- dependent transcriptional mechanism ${ }^{8}$

\section{PATIENTS AND METHODS}

This study was approved by the local Ethical Committee in Nineveh Directorate of the Health.In this case control study a total of 40 newly diagnosed lymphoma patients (Hodgkin and NonHodgkin Lymphoma), who attended to AL-Mosul Oncology, Nuclear Medicine hospital, Ibn Sina Hospital and Private Clinic, were included in this study during a period of eight months (October 2019 - April 2020). Their ages ranged between (16-83) years. The control group were 40 age and sex matched healthy subjects who were recruited from blood donors, academic staff and medical staff. The diagnosis of cases was made by full medical history, physical examination and lymph node (LN) biopsy examination with immunohistochemistry (I.H.C.) by consultant histopathologist , blood film, bone marrow aspiration (BMA) and bone marrow biopsy (BMB) examination by consultant hematopathologist. The criteria for inclusion of the patients was that all thepatients were diagnosed as lymphoma depe on histopathological examination of L.N biopsy with I.H.C and hematopathological examination of B.M.A and B.M.B with immunephenotyping on blood picture (B.P) or B.M.A. sample also all patients were newly diagnosed not receiving chemotherapy before the time of collecting blood sample and Indiscriminately chose with respect to age, gender, stage of the disease. Bone marrow (B.M) involvement and the degree of anemia.For exclusion criteria was patients with Lymphoma who received chemotherapy and lymphoma patients with hemolytic anemia (confirmed by high retic count). Blood sampling and processing by using a disposible plastic syringe with clean venipuncture technique, $10 \mathrm{ml}$ of venous blood sample were collected, Complete blood count and Retic count were done in all participants. All hematological tests were done on the same day of collection of each sample and were carried out according to standard procedure by Bain and lewis ${ }^{9}$. The level of IL- 6 was performed by using enzyme-linked immunosorbent assay(ELISA) technique at Immunology Department using Human Interleukin 6(IL-6) ELISA Kit ${ }^{10}$.

\section{Statistical Analysis}

Statistics is one of the important sciences in decision-making by clarifying the relationships resulting from the study as in this study analysis of data was carried out using the available statistical package of SPSS-26 (Statistical Packages for Social Sciences- version 26).

Data were offered in simple measures of frequency, percentage, mean, standard deviation, and range (minimum-maximum values). Studentst-test, ANOVA test and Pearson Chi-square test are used in this study.

Statistical significance was measured whenever the probability value of ( $\mathrm{P}$ - value) was equal or less than $(0.05,0.01)$ as well as using the charts represented by (Bar Charts) to illustrate the difference or similarity between the studied cases of normal patients Special tables were included for the study. 


\section{RESULTS}

The mean age of lymphoma patients was (44.95干19.59);ranged from (16-83), mean age for HL patients was $(33.31 \mp 18.30)$. More than half $12(75 \%)$ of cases were in age categories 45 years and below while the mean age for NHL patient was (52.70干16.60), $17(70.8 \%)$ of cases were in age categories 45 years and above.

$25(62.5 \%)$ were males and 15 (37.5) were females, M: F was 1.6: 1. In $\mathrm{HL}$ group 8 (50\%) were female and 8 (50\%) were males, M:F ratio was 1:1. Regarding NHL patients 17 (70.8\%) were males and 7 (29.2\%) were female, $M: F$ ratio2.4:1. , table (1) shows hematological parameter in lymphoma patients ,about 25(62.5\%) were anemic with hemoglobin level below $12 \mathrm{~g} / \mathrm{dl}$, $10(62.5 \%)$ patients from $16 \mathrm{HL}$ patients were anemic. Table(2)show types of anemia in lymphoma patients; $21(84 \%)$ had normochromic normocytic (NN) anemia; 4(16\%) had hypochromic microcytic (HM) anemia.

RegardingIL-6 . Figure (3) reveals a comparison of IL- 6 mean level between lymphoma patients and their healthy controls. IL-6 mean level was (223.61干82.2) in lymphoma patients the range was (80.00-350.00).IL-6 mean level was $76.66 \mp 16.135$ in healthy controls and the range was (36.40-96.80). There was significant difference between the mean level of IL-6 of lymphoma cases and the mean level of IL- 6 of controls independent of the presence of anemia $(P=0.000)$.

IL-6 level show strong positive relationship with the stage of the disease $(P=0.04)$, and had significant difference with $B$ - symptoms $(P=0.05)$ Table (3). In correlation with heamoglobin $(\mathrm{Hb})$ level .IL-6 level was significantly higher in patients with hemoglobin $<12 \mathrm{~g} / \mathrm{dl}$ than patients group with hemoglobin $\geq 12 \mathrm{~g} / \mathrm{dl}$. IL-6 level was inversely correlated with the heamoglobin level $(P=0.03)$. Figure(4).

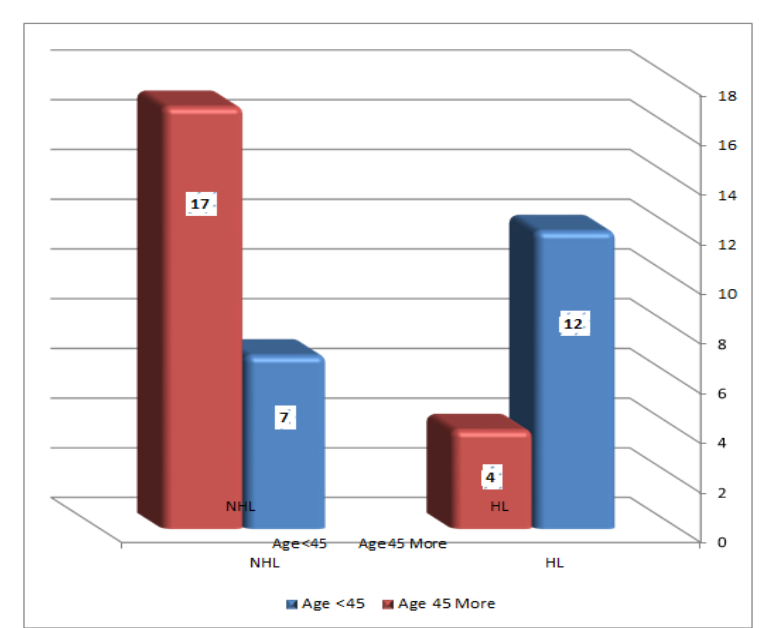

Figure (1): Age distribution in HL and NHL patients.

Table (1): Hematological parameter in lymphoma patients.

\begin{tabular}{|c|c|c|}
\hline \multicolumn{3}{|l|}{ Lymphoma } \\
\hline & Mean \pm & Range \\
\hline Hemoglobin(g/dl) & $11.48 \pm 2.01$ & $(8.30-16.60)$ \\
\hline$\overline{M C V ~ f l}$ & $83.50 \pm 6.79$ & $(68.6-93.9)$ \\
\hline $\mathrm{MCH}$ pg & $27.1 \pm 3.10$ & $(20.6-31.0)$ \\
\hline Retic(\%) & $1.22 \pm 0.38$ & $(0.8-2.0)$ \\
\hline
\end{tabular}

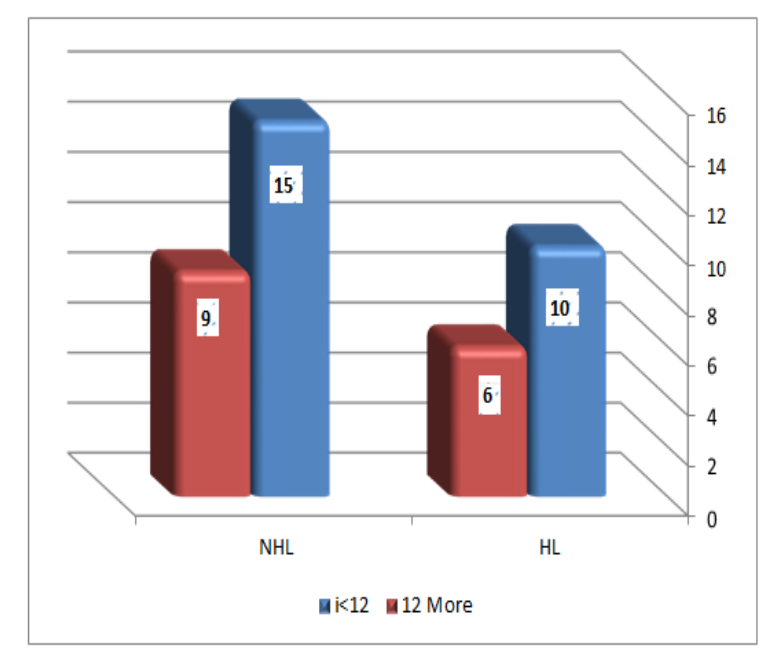

Figure (2): The frequency of anemia in $\mathrm{HL}$ and NHL patients. 
Table (2): Types of Anemia in Lymphoma Patients.

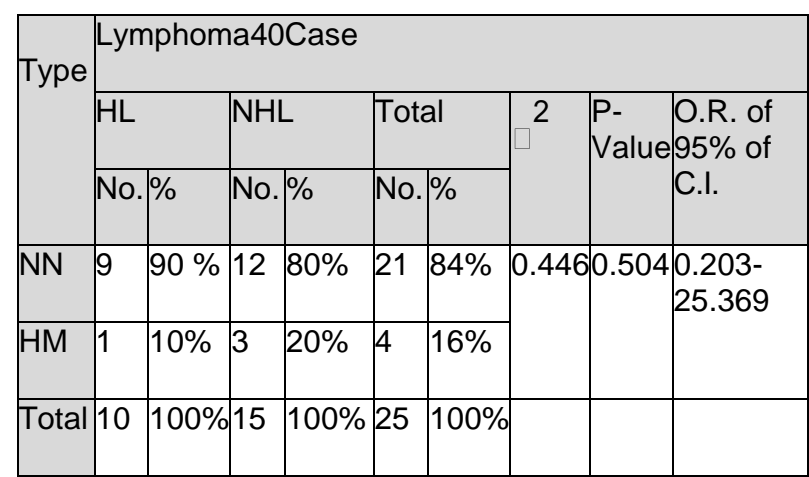

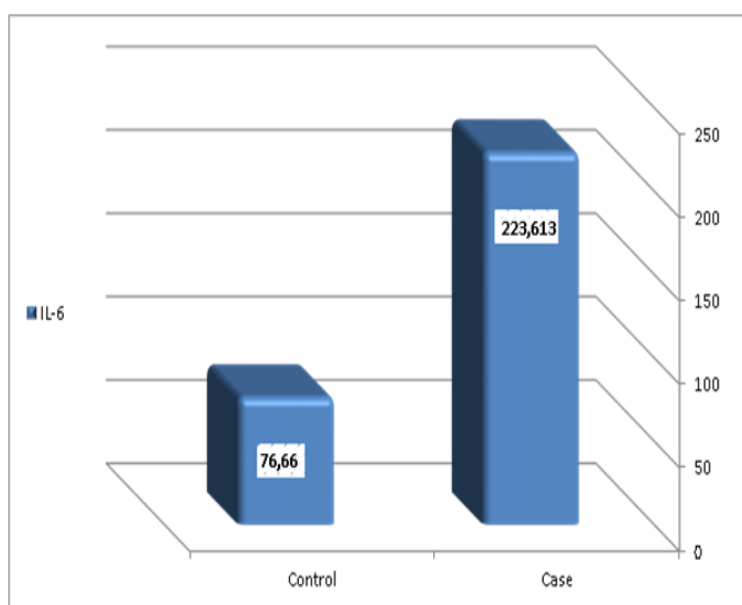

Figure (3): IL-6 level difference between lymphoma cases and healthy controls

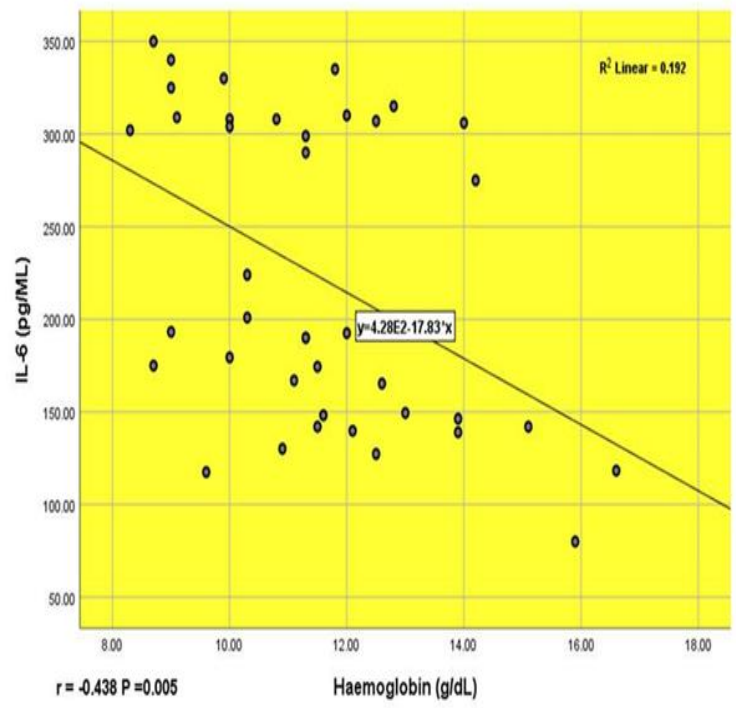

Figure (4): Relationship between IL-6 and $\mathrm{Hb}$ in lymphoma patients.
Table (3): relationship between IL-6 with other variable in lymphoma cases.

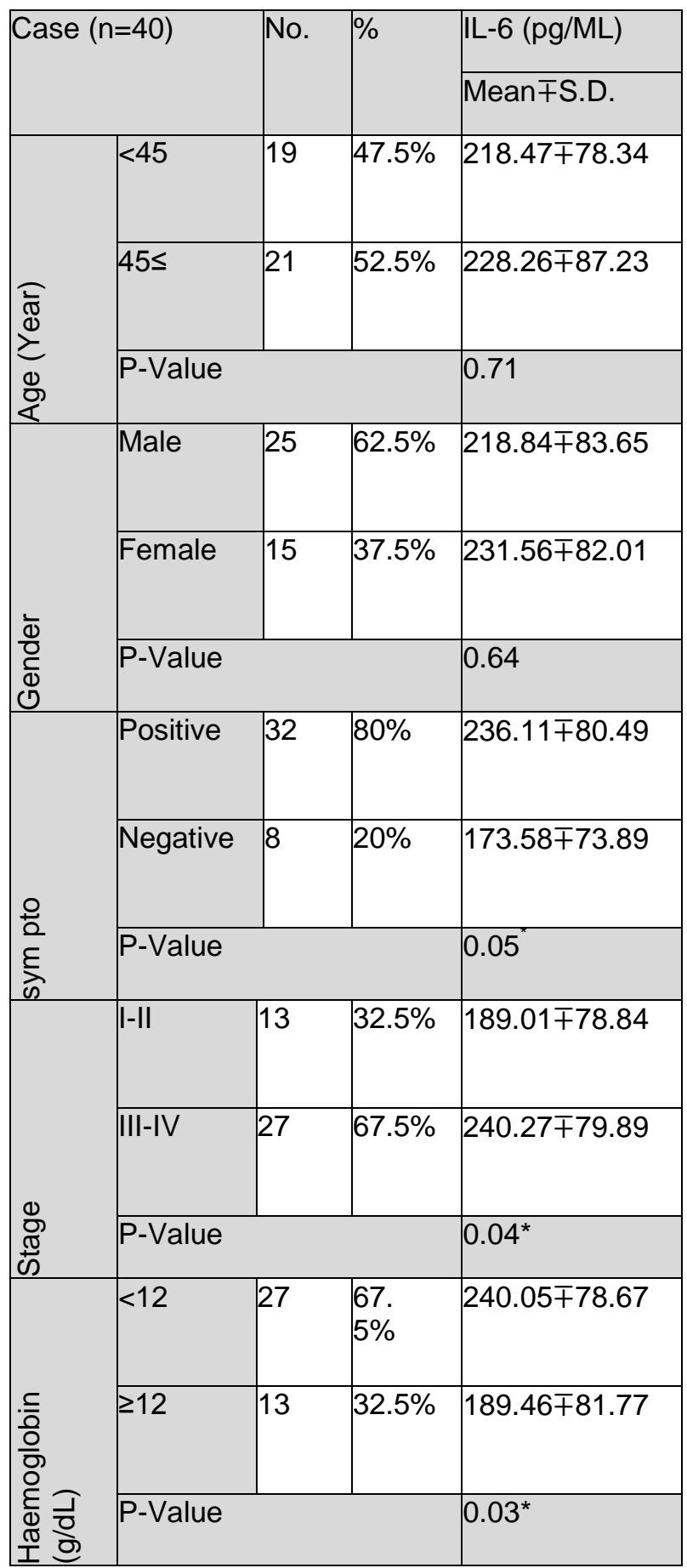




\section{DISCUSSION}

Anemia is a serious and common complication in patients with lymphoma

In the current study, the mean age for $\mathrm{HL}$ patients were (33.31) years and the range was (1673) year. This finding is in line with that reported in 2014 by Fadhil, et al. ${ }^{11}$ who found that the mean age for $\mathrm{HL}$ was (32) year. Also, it is comparable with the finding of Iraqi Cancer Registry (2009) who found that the range of age for $\mathrm{HL}$ was (5-70) year. In addition, these findings are consistent with that reported by Yaqo, et al. in $2011^{13}$ who found that the range of age was (2.6-76) year. However, the higher age of the lower limit, which seen in this study may be clarified by the fact that collection of cases was from Ibn Sina Hospital and private clinics as both of them deal with adult patients.

In this study, the mean age for NHL patients were (52.70) year and the range was (23-83) year. This finding is comparable with both a study done in 2014 by Alwan, et al. ${ }^{14}$ who found that mean age for NHL was (51.44) and with a study done in 2014 by Kamil, et al. ${ }^{15}$ who found that the peak percentage of the patients was $>50$ age group.

Regarding sex of the patients in this current study, male to female ratio for HL patient was (1:1). This finding is, actually, comparable with a study done in 2008 by Biggar, et al. ${ }^{16}$ who found that male and female were equally signified. But, it disagrees with both Yaqo, et al. in $2011^{13}$ who found that male to female ratio was $(3: 1)$ and Fadhil, et al. in $2014^{11}$ who found that male predominance with male to female ratio was $(1.6: 1)$. This difference with our study may be explained by using a smaller size sample because of the limited time taken for the collection of cases and mainly newly diagnosed cases.

This study showed that male to female ratio for $\mathrm{NHL}$ patients was $(2.4: 1)$. This agrees with the finding of Iraqi Cancer Registry (2009) ${ }^{12}$ that found that male to female ratio was $(2: 1)$. Too, it agrees with Yaqo, et al. in $2011^{13}$ who found that a male predominance with male to female ratio was $(2: 1)$. Likewise, it agrees with a study done by Alwan, et al. in $2014^{14}$ who found a male predominance in NHL patient. Conversely, this finding doesn't agree with a study done in 2014 by Kamil TS, et al. ${ }^{15}$ who found that there was no significant difference between male and female, which may be due to the use of smaller size sample and the different geographic distribution of the cases.

The current study showed that $16(40 \%)$ patients out of (40) were diagnosed as $\mathrm{HL}$ and $24(60 \%)$ out of (40) were diagnosed as in NHL. This finding is comparable with a study done in 1993 by Kurzrock , et al. ${ }^{17}$, but it disagrees with a study done by Yaqo, et al in $2011^{13}$ who found that $\mathrm{HL}$ patients were about (24\%) from the cases and
NHL was (76\%). Nevertheless, this can be explained by some factors like the use of smaller size sample, the different geographic distribution of the population as we mentioned before.

When Ann-Arbor Staging System applied on the patients of this study, it showed that most of NHL patients $(83.3 \%)$ were with stage (III- IV) disease and $(16.7 \%)$ in stage (I-II). This finding is in line with study done by Pedersen LM and Sorensen in $2003^{18}$ who found that most of the patients were suffering from Stage-IV disease. This finding, however, disagrees with a study done in Denmark by.Ishtiaq, et al. in $2017^{19}$ on 113 lymphoma patients. The Ann Arbor Stage was evaluated as stage I in 32 patients $(28.3 \%)$, II in 35 patients $(31 \cdot 0 \%)$, III in 28 patients $(24 \cdot 8 \%)$ and IV in 18 $(15 \cdot 9 \%)$ patients. The higher percentage of the patients with advanced stage (III-IV) can be explained by the absence of routine checkup indicated to the late diagnosis in Iraqi patients, and thus they frequently presented with advanced clinical stage.

In this study, the percentage of $\mathrm{HL}$ patients with stage (III-IV) disease was (43.75\%) and with stage (I-II) $(56.25 \%)$. This finding agrees with a study done by Hohaus, et al. in $2010^{20}$. The highest percentage of $\mathrm{HL}$ patients with Stage (III-IV) can be justified by the lack of routine checkup due to the late diagnosis in Iraqi patients, the usually presented with advanced clinical stage.

Regarding to anemia in lymphoma patients, it was found that about $(62.5 \%)$ of patients were anemic and their $\mathrm{Hb}$ less than $12 \mathrm{~g} / \mathrm{dl}$. This finding agrees with a study done by Ludwig , et al. in 2014 ${ }_{21}$ who found that $(67 \%)$ of patients showed $\mathrm{Hb}$ less than 12 during the assessment. Also, this finding agrees with a study done by Brigegard G. et al. in $2008{ }^{4}$ who found that $(73 \%)$ of patient showed $\mathrm{Hb}$ less than $12 \mathrm{~g} / \mathrm{dl}$ through a 6 months follow up period.

In this study, it was found that $10(50 \%)$ of patients with $\mathrm{HL}$ were anemic with $\mathrm{Hb}$ less than 12 $\mathrm{g} / \mathrm{dl}$. This agrees with Birgegard , et al. in $2008^{4}$ who found that that $(57 \%)$ of the $\mathrm{HL}$ patients had $\mathrm{Hb}$ less than $12 \mathrm{~g} / \mathrm{dl}$. Besides, this agrees with Hohaus, et al. in 2010(20) who found that about half of the patient with $\mathrm{HL}$ were anemic. Additionally, in the current study, 15 (62.5\%) of patients with NHL were anemic. This result agrees with a study done by Birgegard, et al. in 2008(4) who found that frequency of anemia in $\mathrm{NHL}$ patients were $(77.9 \%)$.

In this study, 4 (16\%) patients had hypochromic microcytic anemia and $21(84 \%)$ patients had normochromic normocytic anemia. These findings are in agreement with two studies done by both Hohaus, et al. in $2010^{20}$ and Camaschella, et al. in 201622 who found that normochromic 
normocytic anemia was around two third of the patients. Also, the high percentage of normochromic normocytic anemia can be explained by the fact that the Anemia of Chronic Disease (ACD) is commonly normochromic normocytic and occasionally hypochromic microcytic. In this study the mean levels of IL-6 was much higher in lymphoma patients compared to healthy controls and this agrees with studies done by Hohaus, et al. in $2010^{20}$, Biggar, et al. in $2008{ }^{16}$, kurzrock, et al. in $1993{ }^{17}$, Guney, et al. in $2009^{23}$ and Hara, et al. in $2015^{24}$. This study also showed an inverse correlation between both IL-6 mean level with $\mathrm{Hb}$ level. This finding agrees with a study by Hohaus, et al. in $2010{ }^{20}$ who found that IL-6 mean level were higher in anemic H.L patients related to not anemic H.L patient. Too, this finding is compatible with a study done by Ibricevic - balic , et al. in $2016{ }^{25}$ who found that IL-6had particular role in development of anemia in lympho-proliferative disorder. In addition, it agrees with Tisi, et al. in $2014{ }^{26}$ who found that IL-6 concentration inversely correlated to $\mathrm{Hb}$ rate and IL-6 play a major role in the development of anemia by suppression of BM and reduce erythropoietin synthesis. Furthermore, in this study, there was positive correlation between IL- 6 mean level with stage of the disease. This finding agrees with Hohaus, et al. in $2010^{20}$ who found that IL-6 had positive correlation with stage of disease in H.L patient. Also, it goes with Bigger, et al. in 2008 ${ }^{16}$ who found that IL-6 level was associated with more advanced stage and agrees with Aydin, et al. in $2002{ }^{27}$ who found that IL-6 level was higher in advanced stage. Thus, it concludes that the elevated level of IL- 6 in patients with advanced stage disease may represent a prognostic marker. Similarly, in this study, we found that there was positive correlation between IL-6 mean levels with B-symptoms. This finding agrees with a study by Hohaus, et al. in $2010^{20}$ who found IL-6 correlated positively with B-symptoms. Contrariwise, in this study, there was no significant correlation between IL-6 levels with age group. This finding is found to be against a study done by Hohaus, et al. in 2010 ${ }^{20}$ who found a direct relation between IL- 6 and age group [ $>$ or $<45$ ] in $65 \mathrm{HL}$ patients. This, nonetheless, may be explained by the use of a smaller size sample and variance between age groups. On the other side, IL-6 showed no significant relation with sex in this study. This, actually, goes with a study by Hadi , et al. in 2013 ${ }_{28}$ who found the same relation between sex and IL-6.

\section{CONCLUSIONS}

IL-6 level is high in lymphoma patients compare to control.Its level is significantly inversely correlation with Hb.IL-6 plays an important role in the development of anemia in lymphoma.the adverse impact of elevated IL- 6 is consistent with significantly positive correlation with advanced stage of disease. It can be a prognostic factor and The level of IL-6 is significantly positive correlation with B-symptoms .

\section{RECOMMENDATIONS}

Further study is needed to examine the correlation between IL-6 level and phenotypic characteristics as well as the outcomes of lymphoma patients, to evaluate serum level of IL-6, IL-10 and IL-13 before and after HL treatment and to determine their potential association with clinical and laboratory parameter and larger scale research is needed in this field to provide new knowledge.

\section{REFERENCES}

1.Goldblum J, Lamps L, McKenney J, Myers J. Rosai and Ackerman's surgical pathology. Surgical Pathology 11th Ed. US: Elsevier 2011 ;2: 1806.

2.Marcus R, Sweetenham JW, Williams ME. Editors. lymphoma pathology, diagnosis and treatment.1st Ed. UK: Cambridge 2007 ; 3-37.

3. Connors JM. Clinical manifestations and natural history of Hodgkin's lymphoma. Cancer Journal (Sudbury, Mass.). 2009;15(2):124-8.

4. Bigergard G. Managing anemia in lymphoma and multiple myeloma. Therapeutics and clinical risk management. 2008;4(2):527-39

5.Ganz T . Hepcidin, a key regulator of iron metabolism and mediator of anemia of inflammation. Blood. 2003;102(3):783-8.

6. Casasnovas RO, Monnier N, Brice P, Pauline Brice, Marine Divine, Franck Morschhause, et al . Plasma Cytokine and Soluble Receptor Signature Predicts Outcome of Patients With Classical Hodgkin's Lymphoma. Journal of Clinical Oncology. 2007 ; 25: 1732-40.

7. Guo Y, Xu F, Lu T, Duan Z, Zhang Z. Interleukin6 signaling pathway in targeted therapy for cancer. Cancer Treatment Reviews. 2012; 38(7):904-10.

8. Wrighting DM, Andrews NC. Interleukin-6 induces hepcidin expression through STAT3. Blood. 2006 ;108(9):3204-9.

9. Bain BJ, Bates I, Laffen MA. Preparation and staining method for Blood and bone marrow film. Dacie and Lewis Practical Haematology. 12th Ed. Elsevier 2017; 4: 50-61. 
10. Human interleukin 6(IL-6) ELISA Kit. MyBiosource, Inc.San Diego,USA. Available at Email:Sale@mybiosource.com

11. Fadhil MS, Al-Nueimy WM, Lazim AF. Hodgkin's lymphoma. An immunohistochemical profile in northern Iraq. Saudi Medical Journal. 2014; 35(5): 448-453

12. Results of Iraqi Cancer Registry.Iraqi Cancer board, Iraqi Cancer Registry Centre, Ministry of Health, Baghdad-Iraq .2009:133-148

13. Yaqo RT, Hughson MD, Sulayvani FK, AlAllawi NA. Malignant lymphoma in northern Iraq: a retrospective analysis of 270 cases according to the World Health Organization classification. Indian Journal Cancer. 2011; 48(4):446-51

14. Alwan AF, Al-Rahal NK, Shabeeb ZA. Incidence of Epstein Barr Virus infection in newly diagnosed non-Hodgkin lymphoma in the national center of hematology-single center study . Iraqi Journal of Cancer and Medical Genetics. 2014; 7: 21-5.

15. Kamil TS, Al-rawi RA, Alhaideri M. Immunohistochemical and clinicopathological study of non-Hodgkin's lymphoma in Erbil, Kurdistan. Zanco Journal of Medical Sciences. 2014; 18(2): 756-62.

16. Biggar RJ, Johansen JS, Smedby KE, Rostgaard K, Chang ET, Adami HO, et al . Serum YKL-40 and interleukin 6 levels in Hodgkin lymphoma. Clinical cancer research : an official journal of the American Association for Cancer Research. 2008; 14(21):6974-8.

17. Kurzrock R, Redman J, Cabanillas F, Jones D, Rothberg J, Talpaz M. Serum IL-6 Are elevated in lymphoma Patients and correlate with survival in Advanced Hodgkin's Disease and with Bsymptoms. Cancer Research. 1993; 53(9): 211822.

18. Pedersen LM, Sorensen PG. Mediators of inflammation correlate with microalbuminuria in patients with non-hodgkins lymphoma . British Journal of Haematology. 2003 ; 121:275-9.

19. Ishtiaq J, Jehanzeb K, Ali N, Alam M . Bone Marrow Infiltration and Pattern in Previously diagnosed Patient of non-hodgkin lymphoma( a single center study). Pak Armed Forces Medical Journal. 2017; 67 (2): 249-52.

20. Hohaus $S$, Massini G, Giachelia M , Vannata B, Bozzoli V , Leone $G$,et al. Anemia in Hodgkin's lymphoma: The Role of Interleukin6 and Hepcidin. Journal of Clinical Oncology. $2010 ; 28(15): 2538-43$.

21. Ludwig $H$, Van Belle $S$, Barrett-Lee $P$, Birgegård $\mathrm{G}$, Bokemeyer $\mathrm{C}$, Gascón $\mathrm{P}$, et al .The European Cancer Anaemia Survey (ECAS): a large, multinational, prospective survey defining the prevalence, incidence, and treatment of anaemia in cancer patients. European Journal of Cancer.2004;40(15):2293-306.

22. Camaschella C, Hoffbrand AV, Hershko C. Iron metabolism, iron deficiency and disorders of haem synthesis. Postgraduate Haematology, 7th Ed. UK: Blackwell Publishing Ltd 2014; 3:26

23. Guney N, Soydinc HO, Basaran M, Bavbek S, Derin D, Camlica $H$, et al .Serum levels of interleukin-6 and interleukin-10 in Turkish patients with aggressive non-Hodgkin's lymphoma. Asian Pacific Journal of Cancer Prevention : APJCP.2009; 10(4):669-74.

24. Hara M, Ando M, Tsuchiya K, Nitta K. Serum hepcidin-25 level linked with high mortality in patients with non-Hodgkin lymphoma. Annals of Hematology. 2015 ;94(4):603-8.

25. Ibricevic-Balic L, Icindic-Nakas E, Hasic S, Kiseljakovic E, Sofo-Hafizovic A, Balic S.Dilemma: Correlation Between Serum Level of Hepcidin and IL-6 in Anemic Myeloma Patients. Medical archives (Sarajevo, Bosnia and Herzegovina). $2016 ; 70(6): 429-32$ •

26. Tisi MC, Bozzol V, Giachelia M, Masseni G, Ricerca BM, Maiolo E,et al. Anemia in diffuse large B-cell non-Hodgkin lymphoma: the role of interleukin-6, hepcidin and erythropoietin. Leukemia and Lymphoma. 2014; 55(2): 270-5.

27. Aydin F, Yilmaz M, Ozdemir F, Kavgaci $H$, Yavuz MN, Yavuz AA. Correlation of serum IL2, IL-6 and IL-10 levels with International Prognostic Index in patients with aggressive nonHodgkin's lymphoma. American Journal of Clinical Oncology. 2002; 25(6):570-2.

28. Hadi DA, Shani WS, Khalaf AA, Abed AH. Serum levels of interleukin-6 and interleukin-10 in adult newly diagnosed Iraqi Non Hodgkin's lymphoma patients. European Journal of Experimental Biology.2013; 3(5):441-6 